\title{
Stereocontrolled photoinduced electron transfer in metal-fullerene hybrids.
}

\author{
A. J. Stasyuk, ${ }^{* a}$ O.A. Stasyuk, ${ }^{b}$ Nazario Martin, ${ }^{C}$ M. Solà*a and A. A. Voityuk*a,d
}

a. Institut de Química Computacional and Departament de Química, Universitat de Girona, C/ Maria Aurèlia Capmany 69, 17003 Girona, Catalonia, Spain.

b. Institute of Organic Chemistry and Biochemistry, Academy of Sciences of the Czech Republic, Flemingovo nám. 2, 16610 Prague, Czech Republic.

c. Departamento de Quimica Orginica I, Facultad de Ciencias Quimicas, Universidad Complutense de Madrid Ciudad Universitaria s/n, 28040 Madrid, Spain.

b. Institució Catalana de Recerca i Estudis Avancats, 08010 Barcelona, Spain.

\begin{abstract}
Photoinduced electron transfer in transition-metal complexes linked to a fullerene moiety is of increasing interest. Recently, several stereoisomers of an Ir-complex exhibiting configurational stability at metal center, which does not undergo epimerization have been synthesized (Angew. Chem. 56, 2136). The presence of multiple electron donor and acceptor sites located at opposite ends with respect to metallic center, creates the prerequisites for the formation of entirely different CT states. Here we report the results of quantum mechanical calculation and detailed analysis of excited-state properties for all stereoisomers of the junction. We found that the stereoisomers demonstrate clearly different charge transfer (CT) properties by photoexcitation. The found photo-stereospecific effects can be used to design new hybrids with different type of photoinduced CT states exhibiting dissimilar activity in photocatalysis.
\end{abstract}

\section{Introduction}

Conversion of the sunlight into chemical potential is considered to be one of the most important and fundamental chemical reactions in nature. ${ }^{1,2}$ It is based on inter- or intra-molecular electron transfer between donor and acceptor parts of the system caused by photoexcitation. Transition-metal complexes of $\operatorname{Ru}(\mathrm{II}))^{3,4} \operatorname{Re}(\mathrm{I}){ }^{5,6}$ and $\operatorname{Ir}(\mathrm{III})^{6,7}$ are among most interesting systems exhibiting photoinduced electron transfer (PET). They are used for example in lighting devices, ${ }^{8,9}$ solar cells, ${ }^{10}$ photoredox catalysis, ${ }^{11,12}$ and sensors. ${ }^{13,14}$ The unique chemical and physical properties of fullerene $\mathrm{C}_{60},{ }^{15-18}$ such as its highly efficient electron acceptor character and electronic absorption throughout the UV-Vis spectral region, have aroused considerable interest in its application in intramolecular PET reactions ${ }^{19-21}$ and make hybrid systems containing both transition-metal complex and fullerene moiety to be of great interest. ${ }^{22-24}$ In particular, chiral metal complexes provide a promising tool in organometallic chemistry due to their pertinence to enantioselective reactions and catalytic applications in organic synthesis. ${ }^{25,26}$ Recent discovery of fullerene $C_{60}$ half-sandwich transition-metal hybrid complexes with chiral centers both on ligand and metal species opens new opportunities not only for metal catalysis but also for PET reactions. ${ }^{24}$ The fact that metallic center in Ir pyrrolidino[3,4:1,2][60]fullerene half-sandwich complexes is not subjected to epimerization provide ample opportunities for using these complexes in photocatalytic 
reactions and therefore the investigation of the nature of excited states for its stereoisomers is essential for understanding PET reaction.

Herein, we report an exhaustive DFT computational study of Ir pyrrolidino[3,4:1,2][60]fullerene halfsandwich complexes with four stereocenters: Ir-metal center, the asymmetric nitrogen atom and two C5 and C2 chiral carbon atoms at the pyrrolidine ring (Figure 1). The stereoisomers demonstrate different photoinduced electron transfer properties.
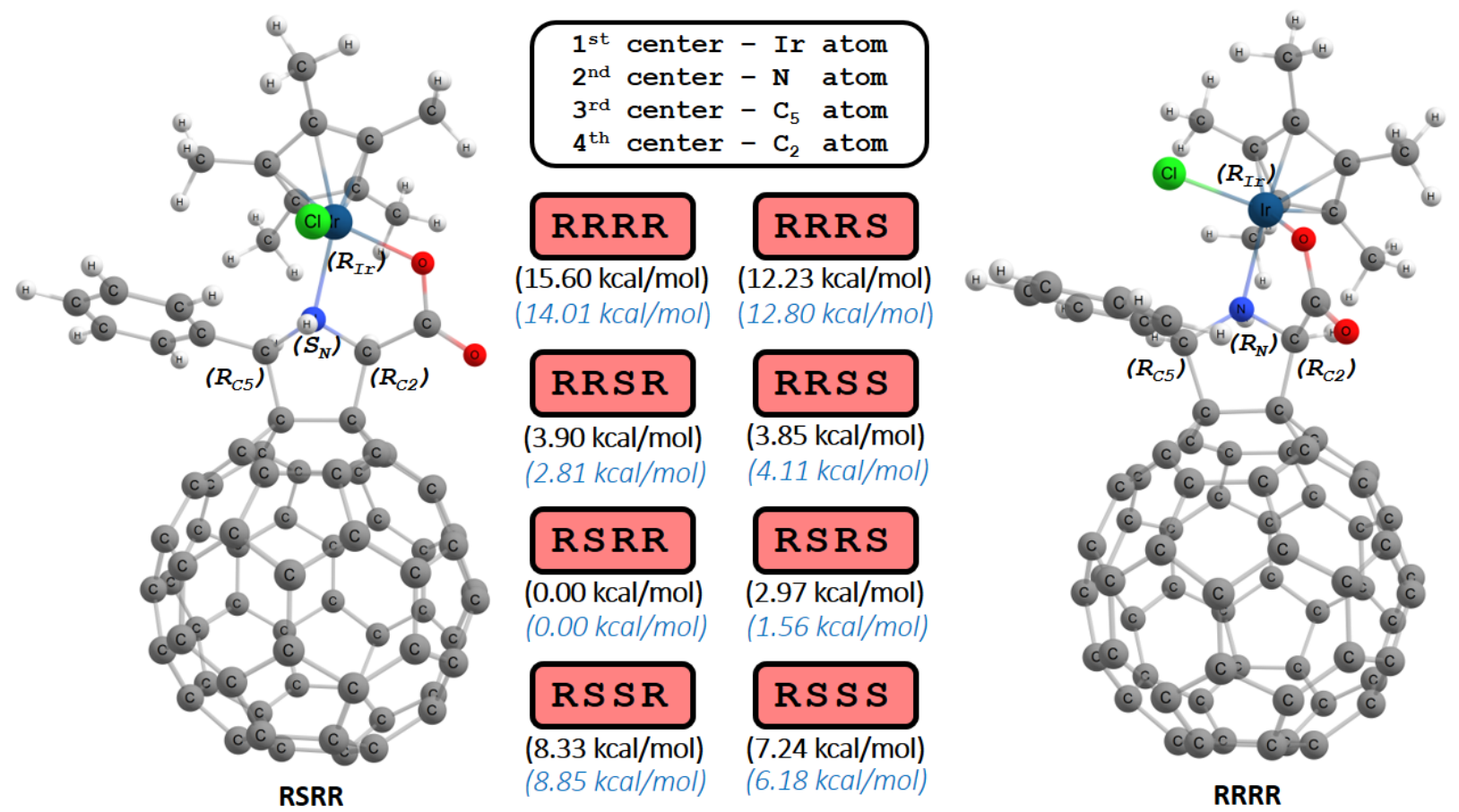

Figure 1. The most stable (RSRR) and least stable (RRRR) stereoisomers of studied Ir-complex as well as relative energies in lowest singlet (bold) and triplet (italic) states for studied stereoisomers, obtained at BLYP-D3(BJ)/def2-SVP level of theory.

\section{Results}

Stability of the stereoisomers. For complex containing four optical centers, there are sixteen possible stereoisomers or eight pairs of enantiomers. Because physical properties of enantiomers are indistinguishable (except for the interaction with polarized light), we consider only 8 stereoisomers. DFT calculations at BLYP-D3(BJ)/def2-SVP level of theory were carried out to gain more insight into the relative stability of the considered isomers in the singlet ground state $\left(\mathrm{S}_{0}\right)$. Calculations revealed that all isomers belong to the less than $16 \mathrm{kcal} / \mathrm{mol}$ energetic range (Figure 1). Studied set of structures can be divided into two groups: low-lying (RSRR, RSRS, RRSS, and RRSR) and high-lying (RSSS, RSSR, RRRS, and RRRR) isomers. In the lowest triplet state $\left(T_{1}\right)$, energy profile for the studied isomers is very similar to the singlet one. RSRR isomer exhibit the greatest stability, while RRRR is less stable with the energy difference between them of about $14 \mathrm{kcal} / \mathrm{mol}$. Regardless of isomer, the singlet state is the lowest-lying state. The $\mathrm{S}_{0}-\mathrm{T}_{1}$ gap is characterized by a value of $28-30 \mathrm{kcal} / \mathrm{mol}$ depending on the isomer (detailed data about relative stabilities of isomers in $\mathrm{S}_{0}$ and $\mathrm{T}_{1}$ states are given in Table $\mathrm{S} 1$ and Figure $\mathrm{S} 1, \mathrm{SI}$ ). According to Martin and co-workers, ${ }^{24}$ relative stability of isomers is determined by two factors acting in different directions: 
(1) strong repulsive interactions between lone pair of $\mathrm{Cl}$ ligand and $\pi$-system of phenyl ring and (2) stabilizing $\mathrm{CH}-\pi$ interactions between $\mathrm{CH}_{3}$ group of methylated cyclopentadienyl ligand and $\pi$-system of phenyl ring. ${ }^{27}$

The studied complexes are unique objects. From one side, four chiral centers open a variety of potential opportunities in the field of (stereo)chemical transformations. ${ }^{26}$ From the other side, a chemical structure of complexes itself, namely the fact that electron acceptors (fullerene $\mathrm{C}_{60}$ and $\mathrm{Cp}^{*}$ ) are located at opposite ends with respect to metallic center, creates the prerequisites for the formation of entirely different CT states with localization of the exciton on different and remote from each other fragments.

Usually for analyzing photoinduced electron transfer (ET) one uses two fragment model consisting of donor and acceptor sides. In this study, a multi-fragment model is applied to examine in detail the role of metal atom and different ligands in ET. Each system has been split into 6 fragments $-\mathrm{Ir}$ and $\mathrm{Cl}$ atoms, pyrrolidine moiety with the carboxyl group, as well as phenyl (Ph), pentamethylcyclopentadienyl (Cp*) and fullerene $\mathrm{C}_{60}$ fragment (Figure 2 ).

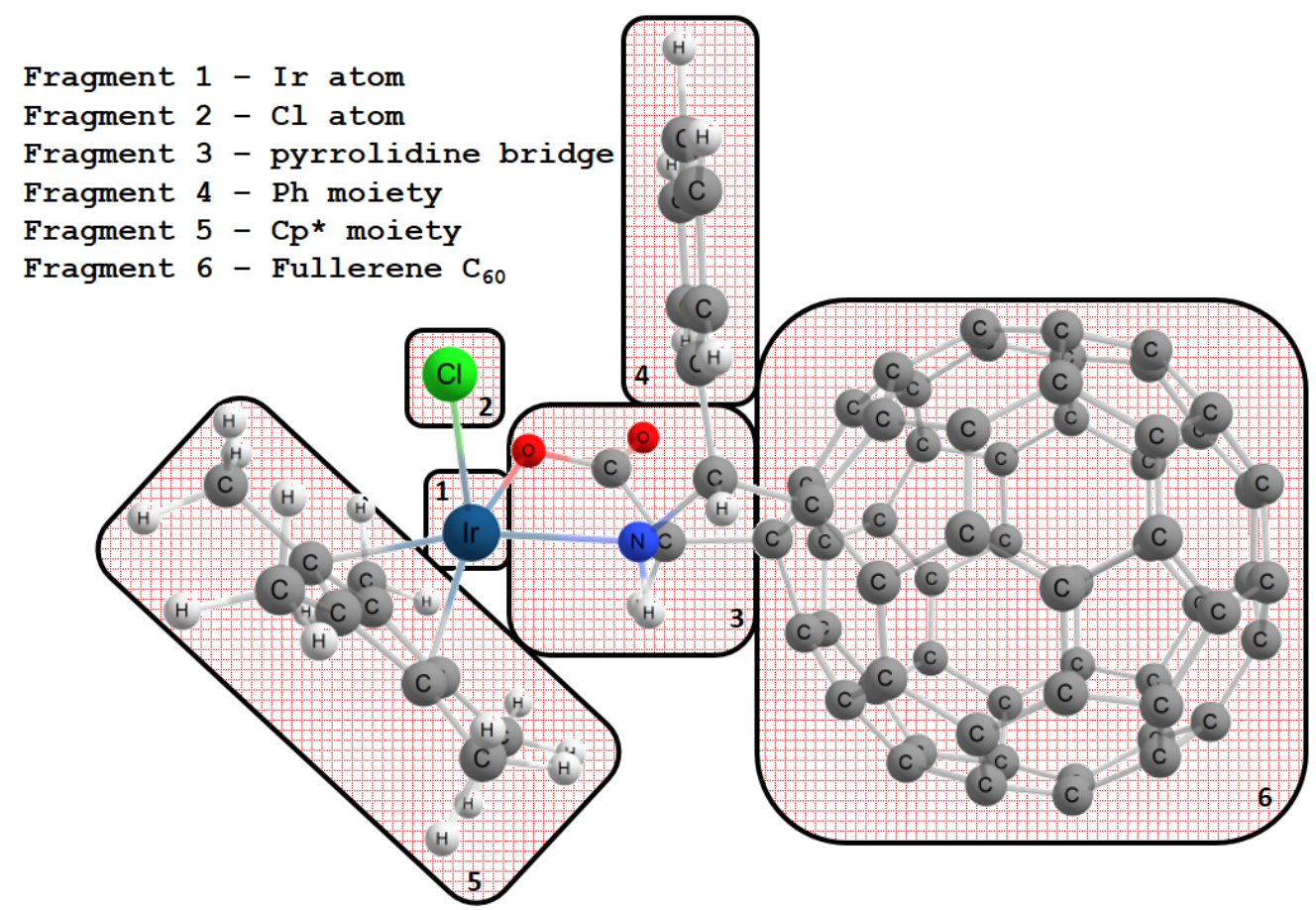

Figure 2. Fragmentation scheme demonstrated by example of RRRR isomer.

$\mathrm{Cp} *$ and fullerene fragments exhibit electron acceptor properties, whereas $\mathrm{Ir}, \mathrm{Cl}, \mathrm{Ph}$ and pyrrolidine bridge fragments are electron donors of different power. Analysis of excited states was carried out in terms of excitation delocalization, charge transfer (CT) and charge separation (CS) contributions. In the studied complexes, several types of excited states can be distinguished: locally excited states (LE), where exciton is mostly localized on a single fragment (in our systems all low-lying LE states are confined on $\mathrm{C}_{60}$ ), excited states corresponding to CT and mixed states, having comparable contributions of LE and CT. Below we considered 50 lowest singlets and triplets excited states for each of isomers.

Singlet states. Predicted 50 lowest singlet excited states for each of eight studied complexes belong to the energy band from 2.4 to $4.6 \mathrm{eV}$ (Table 1 ) in the gas-phase. Several lowest excited states are LE states 
with electronic transitions occurring on $\mathrm{C}_{60}$ fragment. For all isomers, first excited state is mostly associated with HOMO-LUMO transitions. First states demonstrating charge separating characteristics have been found in 3.0-3.2 eV region (Table 1) dependent on isomer. Specified CT states are not pure with respect to the involved fragments, i.e. two fragments simultaneously acts as an electron density donor. In each case, denoted states correspond to the transition of the electron density from metallic center including $\mathrm{Cl}$ ligand to $\mathrm{Cp}$ * moiety. Further, in the energy range of 4.2-4.6 eV the $\mathrm{CT}$ states where electronic transitions metallic center including $\mathrm{Cl}$ ligand to fullerene $\mathrm{C}_{60}$. In the range of $4.4-4.6$ e, electronic transitions from fragment 3 and 4 to fullerene $C_{60}$ are occurred.

Table 1. Singlet excitation energies $\left(E_{x}, e V\right)$ major orbital contributions $(H O M O(H)-L U M O(L))$ and its weight, oscillator strength $(\mathrm{f})$ and charge transfer values $(\mathrm{CT}, \mathrm{e})$, charge values on Ir atom in ground state $(q(I r) G S)$ and changes in Ir charge state $(\Delta q \mathrm{Ir}$, e) for the studied stereoisomers of Ir half-sandwich fullerene $\mathrm{C}_{60}$ complex in the gas-phase. For each transition involved fragments or fragments whose contribution is maximal (Assoc. fragments) are shown.

\begin{tabular}{|c|c|c|c|c|c|c|c|c|}
\hline & \multicolumn{8}{|c|}{ Ir complex } \\
\hline & RRRR & RRRS & RRSR & RRSS & RSRR & RSRS & RSSR & RSSS \\
\hline & \multicolumn{8}{|c|}{$\mathrm{LE}_{1}$} \\
\hline$E_{x}$ & 2.396 & 2.456 & 2.398 & 2.457 & 2.462 & 2.416 & 2.457 & 2.411 \\
\hline $\begin{array}{l}\text { Transition } \\
\text { (weight) }\end{array}$ & $\begin{array}{l}\mathrm{H}-\mathrm{L} \\
(0.82)\end{array}$ & $\begin{array}{l}\mathrm{H}-\mathrm{L} \\
(0.90)\end{array}$ & $\begin{array}{l}\mathrm{H}-\mathrm{L} \\
(0.85)\end{array}$ & $\begin{array}{c}H-L \\
(0.90)\end{array}$ & $\begin{array}{l}H-L \\
(0.89)\end{array}$ & $\begin{array}{l}H-L \\
(0.85)\end{array}$ & $\begin{array}{l}\mathrm{H}-\mathrm{L} \\
(0.90)\end{array}$ & $\begin{array}{c}\mathrm{H}-\mathrm{L} \\
(0.86)\end{array}$ \\
\hline$f$ & 0.006 & 0.004 & 0.006 & 0.004 & 0.005 & 0.006 & 0.004 & 0.006 \\
\hline CT & 0.036 & 0.020 & 0.034 & 0.019 & 0.020 & 0.035 & 0.022 & 0.031 \\
\hline \multirow[t]{2}{*}{$\begin{array}{l}\text { Assoc. } \\
\text { fragments }\end{array}$} & F6 & F6 & F6 & F6 & F6 & F6 & F6 & F6 \\
\hline & \multicolumn{8}{|c|}{$\mathrm{CT}_{(\mathrm{F} 1 \rightarrow F 5)}$} \\
\hline$E_{x}$ & 3.145 & 3.209 & 3.220 & 3.114 & 3.219 & 3.099 & 3.100 & 3.034 \\
\hline $\begin{array}{l}\text { Transition } \\
\text { (weight) }\end{array}$ & $\begin{array}{l}\mathrm{H}-5-\mathrm{L}+7 \\
(0.25)\end{array}$ & $\begin{array}{l}\mathrm{H}-4-\mathrm{L}+8 \\
(0.34)\end{array}$ & $\begin{array}{l}\mathrm{H}-4-\mathrm{L}+8 \\
(0.31)\end{array}$ & $\begin{array}{l}\mathrm{H}-4-\mathrm{L}+7 \\
(0.31)\end{array}$ & $\begin{array}{l}\mathrm{H}-4-\mathrm{L}+7 \\
(0.68)\end{array}$ & $\begin{array}{l}\mathrm{H}-4-\mathrm{L}+7 \\
(0.26)\end{array}$ & $\begin{array}{l}H-4-L+7 \\
(0.51)\end{array}$ & $\begin{array}{l}\mathrm{H}-4-\mathrm{L}+7 \\
(0.44)\end{array}$ \\
\hline$f$ & 0.012 & 0.004 & 0.008 & 0.003 & 0.004 & 0.013 & 0.004 & 0.007 \\
\hline CT & 0.629 & 0.630 & 0.629 & 0.530 & 0.632 & 0.302 & 0.613 & 0.632 \\
\hline \multirow[t]{2}{*}{$\begin{array}{l}\text { Assoc. } \\
\text { fragments }\end{array}$} & $\mathrm{F} 1 \rightarrow \mathrm{F} 5$ & $\mathrm{~F} 1 \rightarrow \mathrm{F} 5$ & $\mathrm{~F} 1 \rightarrow \mathrm{F} 5$ & $\mathrm{~F} 1 \rightarrow \mathrm{F} 5$ & $\mathrm{~F} 1 \rightarrow \mathrm{F} 5$ & $\mathrm{~F} 1 \rightarrow \mathrm{F} 5$ & $\mathrm{~F} 1 \rightarrow \mathrm{F} 5$ & $\mathrm{~F} 1 \rightarrow \mathrm{F} 5$ \\
\hline & \multicolumn{8}{|c|}{$\mathrm{CT}_{(\mathrm{F} 1 \rightarrow \mathrm{F} 6)}$} \\
\hline $\mathrm{E}_{\mathrm{x}}$ & 4.376 & 4.303 & 4.605 & 4.214 & 4.345 & 4.297 & 4.256 & 4.449 \\
\hline $\begin{array}{l}\text { Transition } \\
\text { (weight) }\end{array}$ & $\begin{array}{l}\mathrm{H}-5-\mathrm{L}+1 \\
(0.15)\end{array}$ & $\begin{array}{l}\mathrm{H}-14-\mathrm{L}+1 \\
(0.18)\end{array}$ & $\begin{array}{l}\mathrm{H}-6-\mathrm{L} \\
(0.34)\end{array}$ & $\begin{array}{l}\mathrm{H}-4-\mathrm{L} \\
(0.38)\end{array}$ & $\begin{array}{l}\mathrm{H}-4-\mathrm{L} \\
(0.39)\end{array}$ & $\begin{array}{l}\mathrm{H}-4-\mathrm{L} \\
(0.28)\end{array}$ & $\begin{array}{l}\mathrm{H}-4-\mathrm{L}+1 \\
(0.13)\end{array}$ & $\begin{array}{l}\mathrm{H}-\mathrm{L}+5 \\
(0.10)\end{array}$ \\
\hline$f$ & 0.031 & 0.019 & 0.040 & 0.015 & 0.013 & 0.015 & 0.002 & 0.050 \\
\hline $\mathrm{CT}$ & 0.401 & 0.125 & 0.488 & 0.496 & 0.745 & 0.555 & 0.254 & 0.236 \\
\hline \multirow[t]{2}{*}{$\begin{array}{l}\text { Assoc. } \\
\text { fragments }\end{array}$} & $\mathrm{F} 1 \rightarrow \mathrm{F} 6$ & $\mathrm{~F} 1 \rightarrow \mathrm{F} 6$ & $\mathrm{~F} 1 \rightarrow \mathrm{F} 6$ & $\mathrm{~F} 1 \rightarrow \mathrm{F} 6$ & $\mathrm{~F} 1 \rightarrow \mathrm{F} 6$ & $\mathrm{~F} 1 \rightarrow \mathrm{F} 6$ & $\mathrm{~F} 1 \rightarrow \mathrm{F} 6$ & $\mathrm{~F} 1 \rightarrow \mathrm{F} 6$ \\
\hline & \multicolumn{8}{|c|}{ Most bright CT } \\
\hline$E_{x}$ & 4.479 & 4.482 & 4.427 & 4.498 & 4.425 & 4.436 & 4.436 & 4.613 \\
\hline $\begin{array}{l}\text { Transition } \\
\text { (weight) }\end{array}$ & $\begin{array}{l}\mathrm{H}-1-\mathrm{L}+3 \\
(0.18)\end{array}$ & $\begin{array}{l}\mathrm{H}-1-\mathrm{L}+3 \\
(0.14)\end{array}$ & $\begin{array}{l}\mathrm{H}-1-\mathrm{L}+4 \\
(0.15) \\
\end{array}$ & $\begin{array}{l}\mathrm{H}-1-\mathrm{L}+3 \\
(0.18) \\
\end{array}$ & $\begin{array}{l}\mathrm{H}-4-\mathrm{L}+1 \\
(0.10)\end{array}$ & $\begin{array}{l}\mathrm{H}-10-\mathrm{L}+2 \\
(0.12)\end{array}$ & $\begin{array}{l}\mathrm{H}-1-\mathrm{L}+3 \\
(0.09) \\
\end{array}$ & $\begin{array}{l}\mathrm{H}-2-\mathrm{L}+5 \\
(0.26)\end{array}$ \\
\hline$f$ & 0.167 & 0.110 & 0.143 & 0.086 & 0.102 & 0.101 & 0.122 & 0.087 \\
\hline
\end{tabular}




\begin{tabular}{|l|l|l|l|l|l|l|l|l|}
\hline $\mathrm{CT}$ & 0.174 & 0.322 & 0.183 & 0.105 & 0.315 & 0.175 & 0.314 & 0.171 \\
\hline $\mathrm{q}(\mathrm{Ir}) \mathrm{GS}$ & 0.389 & 0.393 & 0.394 & 0.402 & 0.393 & 0.380 & 0.376 & 0.382 \\
\hline$\Delta \mathrm{q} \mathrm{Ir}$ & 0.036 & 0.069 & 0.043 & 0.010 & 0.111 & 0.048 & 0.066 & 0.031 \\
\hline $\begin{array}{l}\text { Assoc. } \\
\text { fragments }\end{array}$ & $\mathrm{F} 4 \rightarrow \mathrm{F} 6$ & $\mathrm{~F} 3 \rightarrow \mathrm{F} 6$ & $\mathrm{~F} 3 \rightarrow \mathrm{F} 6$ & $\mathrm{~F} 3 \rightarrow \mathrm{F} 6$ & $\mathrm{~F} 1 \rightarrow \mathrm{F} 6$ & $\mathrm{~F} 3 \rightarrow \mathrm{F} 6$ & $\mathrm{~F} 3 \rightarrow \mathrm{F} 6$ & $\mathrm{~F} 3 \rightarrow \mathrm{F} 6$ \\
\hline
\end{tabular}

Thus, for the described system, depending on the excitation energy it is possible to populate charge transfer states with the different character. This can have a significant impact on the behavior of the complex in photoinduced catalytic reactions. However, transitions between molecular orbitals corresponding to the aforementioned (F1 $\rightarrow$ F5 and F1 $\rightarrow$ F6) CT states are characterized by the relatively small probability for the mentioned transitions. On average, oscillator strength for F1 $\rightarrow \mathrm{F} 5$ transitions varies from 0.001 to 0.01 , while for $F 1 \rightarrow F 6$ it is from 0.01 to 0.03 . Low oscillator strength values limit potential usage of this complexes. Then, we decided to check out the "brightest" transitions associated with CT states. For this complex, the strongest oscillator strength is about $0.09-0.17$, dependently on particular isomer. Surprisingly, we have found that only for RSRR isomer most intense transition is relate to $\mathrm{CT}$ state in which electron density is transferred from Ir to fullerene $\mathrm{C}_{60}$. In every other cases, transitions with highest oscillator strength were connected with pyrrolidine bridge (F3) or phenyl ring (F4) to fullerene moiety (F6) (Table 1).Visualization of the described above locally excited states and CT states characterized by F1 $\rightarrow$ F5 as well as F1 $\rightarrow$ F6 transitions for RSRR isomer are shown in Figure 3 .

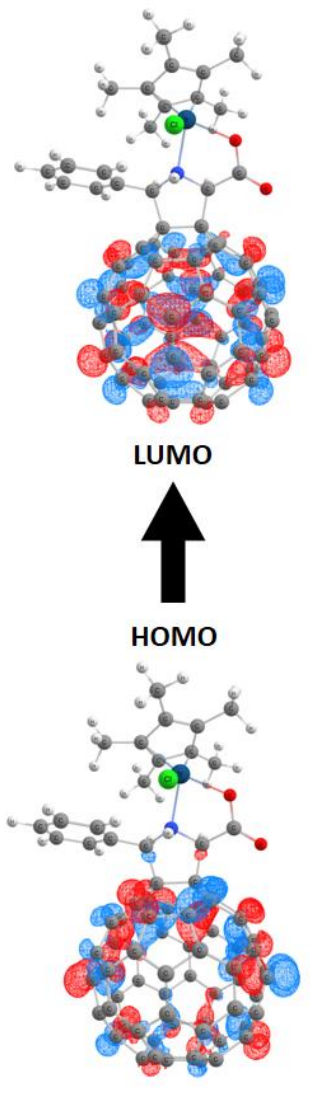

LE

$$
\text { . }
$$

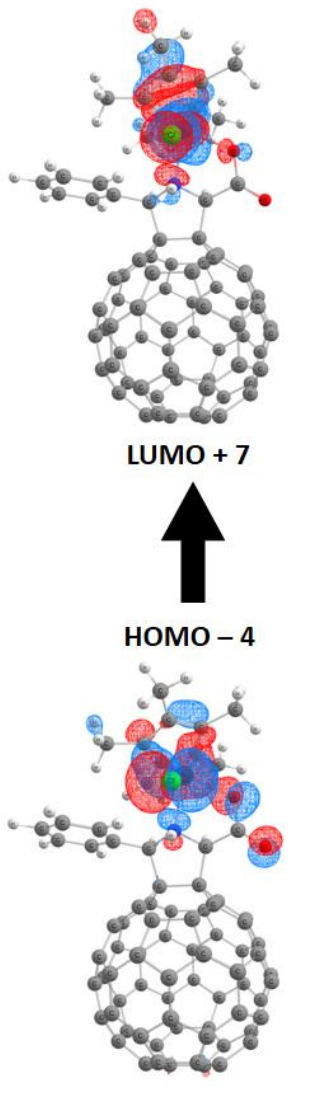

$\mathrm{CT}^{\mathrm{F} 1 \rightarrow \mathrm{F5}}$

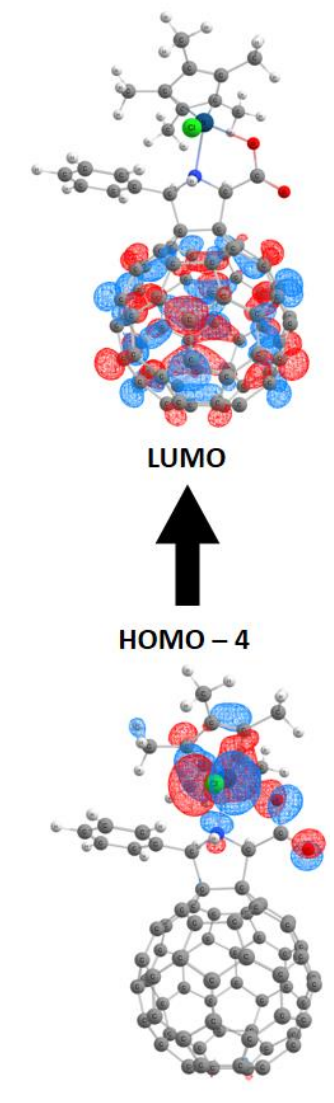

$\mathrm{CT}^{\mathrm{F} 1 \rightarrow \mathrm{F} 6}$ 
Figure 3. Frontier molecular orbitals representing lowest-lying single LE state (left), CT states correspond to F1 $\rightarrow$ F5 (middle) and F1 $\rightarrow$ F6 (right) transitions for RSRR isomer.

The electron density changes observed on Ir atom clearly demonstrate the peculiarity of RSRR stereoisomer. In accordance with Mulliken population analysis, the change of Ir charge in case of RSRR isomer is $0.11 \mathrm{e}$, which is almost twice larger than for any other isomer. At the same time, taking into account that charge on Ir atom in the ground state is about $0.38-0.40$ e, the indicated changes can be considered as significant.

In other words, depending on the isomers we can efficiently generate CT excited states of different nature. Such stereospecificity towards photoinduced electron transfer provides an attractive pathway for photocatalytic reactions, where only one of the stereoisomers demonstrate activity while others remain inactive.

Triplet states. First 50 triplet excited states have been studied as well. Low-lying triplet $\mathrm{LE}^{\top}{ }_{1}$ and $\mathrm{CT}^{\top}$ states show behavior similar to those in the corresponding singlet states. Namely, first triplet excited state is mostly associated with the excitation localized at fullerene $\mathrm{C}_{60}$ moiety and corresponds to HOMO to LUMO+1 transition, while HOMO-LUMO excitation leads to the $3^{\text {rd }}$ triplet LE. Similarly to singlet exited states the lowest charge separated state corresponds to the transition of the electron density from metallic center including $\mathrm{Cl}$ ligand to $\mathrm{Cp}^{*}$ moiety. In contrast to singlet excited states, no one of considered triplet $\mathrm{CT}$ excited states does not correspond to electronic transitions from Ir fragment to $\mathrm{C}_{60}$. Detailed information concerning triplet excited states as well as frontier molecular orbitals representing $\mathrm{LE}^{\top}$ and $\mathrm{CT}^{\mathrm{T}}$ states are given in Table S2 and Figure S2, SI.

Solvent effect. It is well known that solvation may significantly influence both ground and excited states. Usually, the effect of solvation is relatively weak for LE states, while charge transfer states can strongly be stabilized. To assess the solvent effects on the excitation energies the equilibrium solvation model with dichloromethane (DCM) as a solvent has been applied. In the ground state, all of eight studied isomers demonstrate comparable dipole moment in the range from 7.6 to $9.6 \mathrm{D}$, depending on particular isomer. However, despite the fact that dipole moment can vary up to $20 \%$ the changes in solvation energies are only of a few percent (Table S3, S4, SI). The reason for this behavior is apparently the high steric hindrance of the complex due to large ligands that make it difficult for a solvent to access significant parts of the complex. In case of the excited states, the overall picture is very similar. Additionally, taking into account that excited states of interest is mostly associated with metallic center - the most shielded fragment of the complex - solvation energies relatively insensitive to the changes in charge state on this fragment. Comparison between excitation energies computed for the gas phase and solution indicates that LE transition energies remain almost unchanged, in spite of solvation shift for each GS and LE states is noticeable (about $0.7 \mathrm{eV}$ ). Detailed data for all studied complex are provided in Table S3, S4 and Figure S3, SI. Due to the already mentioned reason, CT states demonstrate untypically small shift which is comparable to that for LE states (about $0.7-0.8 \mathrm{eV}$, in case of RSRR isomer the shift is slightly more than $1.0 \mathrm{eV}$ ), despite the fact that significant changes in dipole moments (up to $25 \mathrm{D}$ ) for CT states have been observed. The effect of solvation on triplet excited states, in general, is pretty similar to those observed in singlet excited states. Figure 4 demonstrates LE and CT energies for singlet and triplet excited states both in vacuum and CPCM (DCM) solvent. 


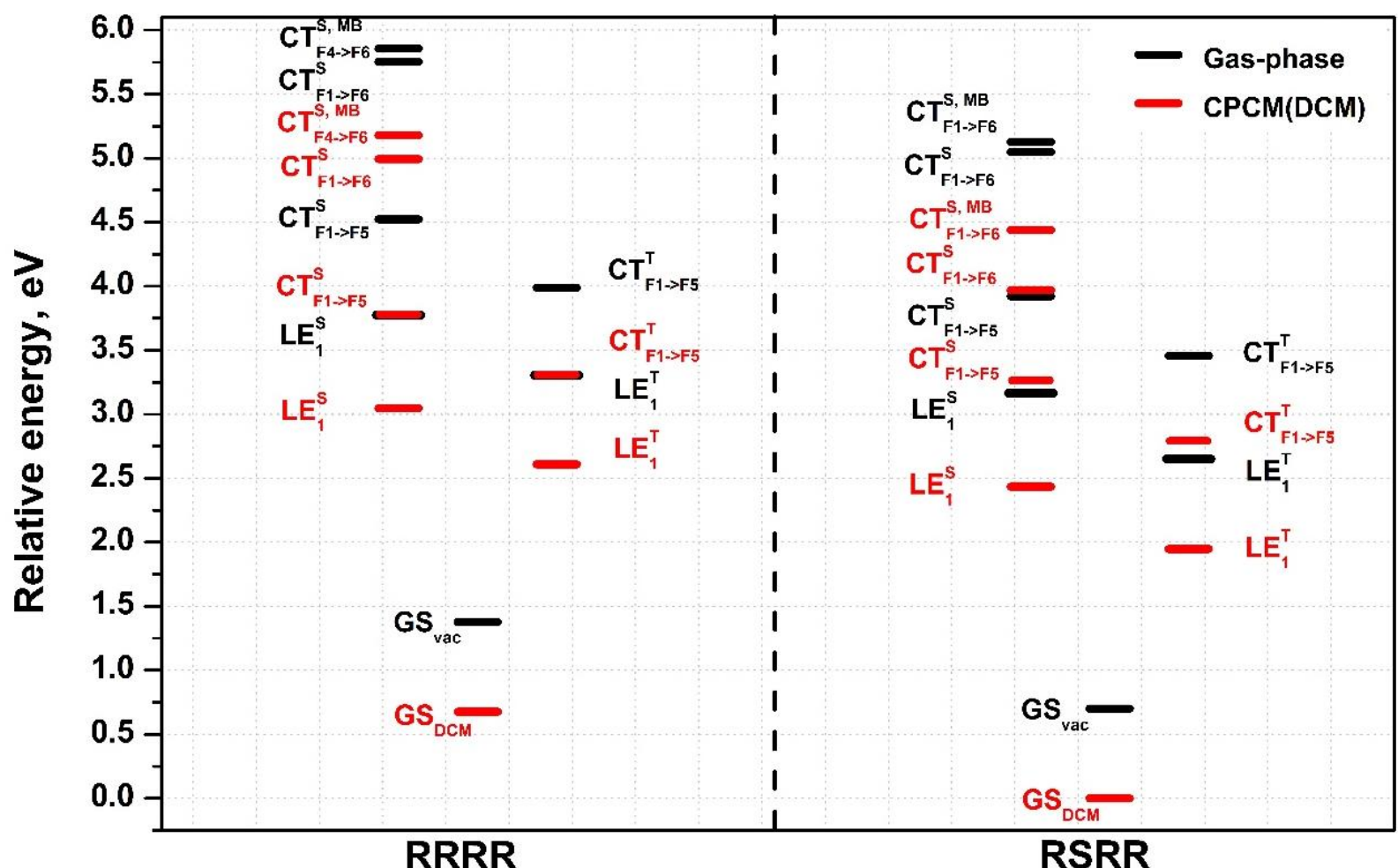

Figure 4. Locally and charge separated excited states energies of Ir pyrrolidino[3,4:1,2][60]fullerene halfsandwich RRRR and RSRR complexes. GS - ground state, $\mathrm{LE}_{1}$ - lowest locally excited state, $\mathrm{CT}_{\mathrm{F} 1 \rightarrow \mathrm{F}_{5}}$ - charge separated excited states corresponded to $\mathrm{F} 1 \rightarrow \mathrm{F} 5$ transitions, $\mathrm{CT}_{\mathrm{F} 1 \rightarrow \mathrm{FG}}$ - charge separated excited states corresponded to $\mathrm{F} 1 \rightarrow \mathrm{F} 6$ transitions, and $\mathrm{CT}^{\mathrm{MB}}{ }_{\mathrm{Fx} \rightarrow \mathrm{Fy}}$ - charge separated excited states with biggest oscillator strength, corresponded to denoted in subscript transitions. Superscript index refers to singlet or triplet excited state.

\section{Conclusions}

Photoinduced charge separated properties of eight stereoisomers of Ir-based half-sandwich [60]fullerene complexes, have been studied in detail using the TDA DFT approach. The effect of solvent on LE and CT states of interest has been also studied. Solvent effect is found not to be crucial for efficient population of singlet and triplet CT states. Unlike other isomers, the RSRR under photoexcitation exhibits an intense transition corresponded to electron transfer from Ir to fullerene moiety, increasing the partial charge on the metal center. For the first time demonstrated stereospecificity towards photoinduced electron transfer paves the way to photo-chemical applications of the transition-metal complexes with chiral centers in stereoselective photocatalysis. We also believe that will stimulate to take a new look on the already known chiral complexes and encourage further experimental and theoretical research of photoinduced properties of such complexes.

\section{Methods}

General. The geometry optimization for all stereoisomers was performed employing the DFT BLYP ${ }^{28,29}$ exchange-correlation functional using the resolution of identity approximation (RI, alternatively termed density fitting) ${ }^{30}$ implemented in the TURBOMOLE 7.0 program. ${ }^{31}$ Vertical excitation energies were calculated using TDA formalism ${ }^{32}$ with the range-separated functional from Head-Gordon and co-workers 
wB97XD ${ }^{33}$ using Gaussian 09 (rev. E01). ${ }^{34}$ Ahlrichs' Def2-SVP basis set. ${ }^{35,36}$ The empirical dispersion D3 correction with Becke-Johnson damping , ${ }^{37,38}$ was employed. All resulted structures visualized with Chemcraft 1.8. ${ }^{39}$

Analysis of excited states. The quantitative analysis of exciton delocalization and charge separation in the donor-acceptor complexes was carried out using a tool suggested recently by Plasser et al ${ }^{40,41} \mathrm{~A}$ key quantity is the parameter $\Omega$ :

$$
\begin{aligned}
& \Omega(\mathrm{A}, \mathrm{B})=\frac{1}{2} \sum_{\alpha \in \mathrm{A}, \beta \in \mathrm{B}}\left[\left(\mathrm{SP}^{0 \mathrm{i}}\right)_{\alpha \beta}\left(\mathrm{P}^{0 \mathrm{i}} \mathrm{S}\right)_{\alpha \beta}+\mathrm{P}_{\alpha \beta}^{0 \mathrm{i}}\left(\mathrm{SP}^{0 \mathrm{i}} \mathrm{S}\right)_{\alpha \beta}\right] \\
& \mathrm{X}\left(\mathrm{F}_{\mathrm{i}}\right)=\sum_{\mathrm{A} \in \mathrm{F}_{\mathrm{i}}} \Omega(\mathrm{A}, \mathrm{A}) \\
& \mathrm{CT}^{\mathrm{F}_{\mathrm{i}} \rightarrow \mathrm{F}_{\mathrm{j}}}=\sum_{\mathrm{A} \in \mathrm{F}_{\mathrm{i}}, \mathrm{B} \in \mathrm{F}_{\mathrm{j}}} \Omega(\mathrm{A}, \mathrm{B})+\Omega(\mathrm{B}, \mathrm{A}) \\
& \mathrm{CS}^{\mathrm{F}_{\mathrm{i}} \rightarrow \mathrm{F}_{\mathrm{j}}}=\sum_{\mathrm{A} \in \mathrm{F}_{\mathrm{i}}, \mathrm{B} \in \mathrm{F}_{\mathrm{j}}} \Omega(\mathrm{A}, \mathrm{B})-\Omega(\mathrm{B}, \mathrm{A})
\end{aligned}
$$

where $\mathbf{P}^{0 i}$ is the transition density matrix for the $\psi_{0} \rightarrow \psi_{\mathrm{i}}$ excitation and $\mathrm{S}$ is the overlap matrix. $\mathrm{X}\left(\mathrm{F}_{\mathrm{i}}\right)$ is the extent of exciton localization on the site $\mathrm{F}_{\mathrm{i}} . \mathrm{CT}^{\mathrm{F}_{\mathrm{i}} \rightarrow \mathrm{F}_{\mathrm{j}}}$ is the weight of $\mathrm{CT}$ configuration in the excited state $\psi_{\mathrm{i}}$. CT means the total amount of the electron density transferred between fragments, while the CS is the amount of the electron density transferred from one fragment to another. Note that in the situation when charge transfer $\left(F_{i} \rightarrow F_{j}\right)$ is equal to the back transfer $\left(F_{j} \rightarrow F_{i}\right)$ there is no charge separation between the fragments, $\mathrm{CS}^{\mathrm{F}_{\mathrm{F}} \rightarrow \mathrm{F}_{\mathrm{j}}}$ is equal to zero.

Solvent Effects. The equilibrium solvation energy $E_{S}^{e q}$ in a medium with dielectric constant $\varepsilon$ was estimated using a COSMO-like polarizable continuum model (C-PCM) in the monopole approximation. ${ }^{42}$

$$
-\mathrm{E}_{\mathrm{S}}^{\mathrm{eq}}(\mathrm{Q}, \varepsilon)=-\frac{1}{2} f(\varepsilon) \mathrm{Q}^{+} \mathrm{DQ}
$$

where the $f(\varepsilon)$ is the dielectric scaling factor, $f(\varepsilon)=\frac{\varepsilon-1}{\varepsilon}, \mathbf{Q}$-the vector of $n$ atomic charges in the molecular system, $\mathbf{D}$ is the $n \times n$ symmetric matrix determined by the shape of the boundary surface between solute and solvent; $\mathbf{D}=\mathbf{B}^{+} \mathbf{A}^{-1} \mathbf{B}$, where the $m \times m$ matrix $\mathbf{A}$ describes electrostatic interaction between $m$ surface charges and the $m \times n \mathbf{B}$ matrix describes the interaction of the surface charges with $n$ atomic charges of the solute. Atomic charges in the excited state $\psi_{\mathrm{i}}$, were calculated using Eq. (1).

\section{Acknowledgements}

We are grateful for financial support from the Spanish MINECO (CTQ2017-85341-P and CTQ2015-69363P projects), the Catalan DIUE (2014SGR931, XRQTC, and ICREA Academia 2014 Award to M.S.), and the FEDER fund (UNGI10-4E-801). A. J. S. gratefully acknowledges The Interdisciplinary Centre for 
Mathematical and Molecular Modelling of the University of Warsaw (ICM) for computational facilities (grant no. G33-17).

\section{References}

1 Marcus, R. A. \& Sutin, N. Electron transfers in chemistry and biology. Biochimica et Biophysica Acta (BBA) - Reviews on Bioenergetics 811, 265-322, doi:https://doi.org/10.1016/03044173(85)90014-X (1985).

2 Moser, C. C., Keske, J. M., Warncke, K., Farid, R. S. \& Dutton, P. L. Nature of biological electron transfer. Nature 355, 796, doi:10.1038/355796a0 (1992).

3 Juris, A. et al. Ru(II) polypyridine complexes: photophysics, photochemistry, eletrochemistry, and chemiluminescence. Coordination Chemistry Reviews 84, 85-277, doi:https://doi.org/10.1016/0010-8545(88)80032-8 (1988).

4 McCusker, J. K. Femtosecond Absorption Spectroscopy of Transition Metal Charge-Transfer Complexes. Accounts of Chemical Research 36, 876-887, doi:10.1021/ar030111d (2003).

5 Stufkens, D. J. \& Vlček, A. Ligand-dependent excited state behaviour of Re(I) and Ru(II) carbonyldiimine complexes. Coordination Chemistry Reviews 177, 127-179, doi:https://doi.org/10.1016/S0010-8545(98)00132-5 (1998).

6 Wenger, O. S. Proton-Coupled Electron Transfer with Photoexcited Metal Complexes. Accounts of Chemical Research 46, 1517-1526, doi:10.1021/ar300289x (2013).

7 Swanick, K. N., Ladouceur, S., Zysman-Colman, E. \& Ding, Z. Self-Enhanced Electrochemiluminescence of an Iridium(III) Complex: Mechanistic Insight. Angewandte Chemie International Edition 51, 11079-11082, doi:10.1002/anie.201206074 (2012).

8 Costa, R. D. et al. Luminescent Ionic Transition-Metal Complexes for Light-Emitting Electrochemical Cells. Angewandte Chemie International Edition 51, 8178-8211, doi:10.1002/anie.201201471 (2012).

9 Tsuboyama, A. et al. Homoleptic Cyclometalated Iridium Complexes with Highly Efficient Red Phosphorescence and Application to Organic Light-Emitting Diode. Journal of the American Chemical Society 125, 12971-12979, doi:10.1021/ja034732d (2003).

10 Hagfeldt, A., Boschloo, G., Sun, L., Kloo, L. \& Pettersson, H. Dye-Sensitized Solar Cells. Chemical Reviews 110, 6595-6663, doi:10.1021/cr900356p (2010).

11 Goez, M., Kerzig, C. \& Naumann, R. An "All-Green" Catalytic Cycle of Aqueous Photoionization. Angewandte Chemie International Edition 53, 9914-9916, doi:10.1002/anie.201405693 (2014).

12 Yoon, T. P., Ischay, M. A. \& Du, J. Visible light photocatalysis as a greener approach to photochemical synthesis. Nature Chemistry 2, 527, doi:10.1038/nchem.687 (2010).

13 Magnuson, A. et al. Biomimetic and Microbial Approaches to Solar Fuel Generation. Accounts of Chemical Research 42, 1899-1909, doi:10.1021/ar900127h (2009).

14 Ramón-Márquez, T., Marín-Suárez, M., Fernández-Gutiérrez, A. \& Fernández-Sánchez, J. F. in Iridium(III) in Optoelectronic and Photonics Applications 479-539 (John Wiley \& Sons, Ltd, 2017).

15 Guldi, D. M. Fullerene-porphyrin architectures; photosynthetic antenna and reaction center models. Chemical Society Reviews 31, 22-36, doi:10.1039/B106962B (2002).

16 Gunes, S., Neugebauer, H. \& Sariciftci, N. S. Conjugated polymer-based organic solar cells. Chemical Reviews 107, 1324-1338, doi:10.1021/cr050149z (2007).

17 Peet, J. et al. Efficiency enhancement in low-bandgap polymer solar cells by processing with alkane dithiols. Nature Materials 6, 497-500, doi:10.1038/nmat1928 (2007). 
Thompson, B. C. \& Frechet, J. M. J. Organic photovoltaics - Polymer-fullerene composite solar cells. Angewandte Chemie-International Edition 47, 58-77, doi:10.1002/anie.200702506 (2008). Abrusci, A. et al. High-Performance Perovskite-Polymer Hybrid Solar Cells via Electronic Coupling with Fullerene Monolayers. Nano Letters 13, 3124-3128, doi:10.1021/nl401044q (2013). Shoaee, S. et al. Charge Photogeneration for a Series of Thiazolo-Thiazole Donor Polymers Blended with the Fullerene Electron Acceptors PCBM and ICBA. Advanced Functional Materials 23, 3286-3298, doi:10.1002/adfm.201203148 (2013).

Zhou, H. X., Yang, L. Q. \& You, W. Rational Design of High Performance Conjugated Polymers for Organic Solar Cells. Macromolecules 45, 607-632, doi:10.1021/ma201648t (2012).

Balch, A. L. \& Olmstead, M. M. Reactions of transition metal complexes with fullerenes (C-60, C70, etc.) and related materials. Chemical Reviews 98, 2123-2165, doi:10.1021/cr960040e (1998). Yeh, W.-Y. Coordination and reactivity of functionalized fullerenes, open-cage fullerenes, and endohedral metallofullerenes by organometallic complexes. Journal of Organometallic Chemistry 784, 13-23, doi:https://doi.org/10.1016/j.jorganchem.2014.09.039 (2015).

Marco-Martínez, J., Vidal, S., Fernández, I., Filippone, S. \& Martín, N. Stereodivergent-at-Metal Synthesis of [60]Fullerene Hybrids. Angewandte Chemie International Edition 56, 2136-2139, doi:10.1002/anie.201611475 (2017).

Bauer, E. B. Chiral-at-metal complexes and their catalytic applications in organic synthesis. Chemical Society Reviews 41, 3153-3167, doi:10.1039/C2CS15234G (2012).

Tian, C., Gong, L. \& Meggers, E. Chiral-at-metal iridium complex for efficient enantioselective transfer hydrogenation of ketones. Chemical Communications 52, 4207-4210, doi:10.1039/C6CC00972G (2016).

27 Tsuzuki, S., Honda, K., Uchimaru, T., Mikami, M. \& Fujii, A. Magnitude and Directionality of the Interaction Energy of the Aliphatic $\mathrm{CH} / \pi$ Interaction: Significant Difference from Hydrogen Bond. The Journal of Physical Chemistry A 110, 10163-10168, doi:10.1021/jp064206j (2006).

28 Becke, A. D. Density-functional exchange-energy approximation with correct asymptotic behavior. Physical Review A 38, 3098-3100 (1988).

29 Lee, C., Yang, W. \& Parr, R. G. Development of the Colle-Salvetti correlation-energy formula into a functional of the electron density. Physical Review B 37, 785-789 (1988).

30 Eichkorn, K., Treutler, O., Öhm, H., Häser, M. \& Ahlrichs, R. Auxiliary basis sets to approximate Coulomb potentials. Chemical Physics Letters 240, 283-290, doi:https://doi.org/10.1016/00092614(95)00621-A (1995).

31 TURBOMOLE 7.0 2015, a development of the University of Karlsruhe and Forschungszentrum Karlsruhe GmbH 1989-2007, TURBOMOLE GmbH since 2007; available from http://www.turbomole.com.

Hirata, S. \& Head-Gordon, M. Time-dependent density functional theory within the TammDancoff approximation. Chemical Physics Letters 314, 291-299, doi:https://doi.org/10.1016/S0009-2614(99)01149-5 (1999).

33 Chai, J.-D. \& Head-Gordon, M. Long-range corrected hybrid density functionals with damped atom-atom dispersion corrections. Physical Chemistry Chemical Physics 10, 6615-6620, doi:10.1039/B810189B (2008).

34 Gaussian 09. Rev. E01. (full citation see in SI).

35 Weigend, F. \& Ahlrichs, R. Balanced basis sets of split valence, triple zeta valence and quadruple zeta valence quality for $\mathrm{H}$ to $\mathrm{Rn}$ : Design and assessment of accuracy. Physical Chemistry Chemical Physics 7, 3297-3305, doi:10.1039/B508541A (2005).

36 Weigend, F. Accurate Coulomb-fitting basis sets for $\mathrm{H}$ to Rn. Physical Chemistry Chemical Physics 8, 1057-1065, doi:10.1039/B515623H (2006). 
37 Grimme, S., Antony, J., Ehrlich, S. \& Krieg, H. A consistent and accurate ab initio parametrization of density functional dispersion correction (DFT-D) for the 94 elements H-Pu. The Journal of Chemical Physics 132, 154104, doi:10.1063/1.3382344 (2010).

38 Grimme, S., Ehrlich, S. \& Goerigk, L. Effect of the damping function in dispersion corrected density functional theory. Journal of Computational Chemistry 32, 1456-1465, doi:10.1002/jcc.21759 (2011).

39 Zhurko G. A. Chemcraft 1.80 (build 523b) - graphical program for visualization of quantum chemistry computations. (https://chemcraftprog.com).

40 Plasser, F. \& Lischka, H. Analysis of Excitonic and Charge Transfer Interactions from Quantum Chemical Calculations. Journal of Chemical Theory and Computation 8, 2777-2789, doi:10.1021/ct300307c (2012).

41 Plasser, F., Bäppler, S. A., Wormit, M. \& Dreuw, A. New tools for the systematic analysis and visualization of electronic excitations. II. Applications. The Journal of Chemical Physics 141, 024107, doi:10.1063/1.4885820 (2014).

42 Tomasi, J., Mennucci, B. \& Cammi, R. Quantum mechanical continuum solvation models. Chemical Reviews 105, 2999-3093, doi:10.1021/cr9904009 (2005). 